\title{
¿SOPLA EN VERDAD EL ESPÍRITU DE DONDE QUIERE? ANÁLISIS CRÍTICO DE TRES MODOS DE COMPRENDER LA FENOMENOLOGÍA DE LA RELIGIÓN
}

\section{DOES SPIRIT TRULY ARISE FROM WHERE IT WISHES? A CRITICAL ANALYSIS OF THREE MODES OF UNDERSTANDING THE PHENOMENOLOGY OF RELIGION}

\author{
ÁNGEL E. GARRIDO-MATURANO* \\ CONICET
}

\begin{abstract}
RESUMEN: El artículo estudia tres diferentes formas de entender la fenomenología de la religión que denomina metodológico-hermenéutica, fundamentativo-trascendental y pático-testimonial a través del análisis crítico de ejemplos paradigmáticos de cada una de ellas. El análisis se propone, en primer lugar, exponer los rasgos metodológicos y las diferencias esenciales de cada una de estas tres perspectivas. En segundo lugar, explicita de qué manera la perspectiva pático-testimonial permite conjugar la revelación religiosa y la filosofía fenomenológica y legitima la multiplicidad de manifestaciones confesionales y no confesionales de la religión. Finalmente muestra en qué medida esta tercera perspectiva «disuelve» los problemas de universalidad y fundamentación inherentes a las otras dos.
\end{abstract}

PAlabras Clave: Fenomenología, religión, fundamentación, universalidad, pathos, testimonio.

Abstract: The article studies three different modes of understanding the phenomenology of religion, which are called the methodological-hermeneutical, the founda-

* El autor es miembro del Instituto de Investigaciones Geohistóricas, en Resistencia, Argentina. E-mail: hieloypuna@hotmail.com 
tional-transcendental, and the pathic-testimonial standpoints, by a critical analysis of paradigmatic examples of each view. This analysis attempts, first, to explain the methodological features and the essential differences of each of the three perspectives. Second, the article shows how the pathic-testimonial viewpoint allows a convergence between religious revelation and phenomenological philosophy, and legitimates the manifoldness of confessional and non-confessional manifestations of religion. Finally, it shows how the third viewpoint «dissolves» the problems of universality and foundation that weaken the other two stances.

KEYWORDS: Phenomenology, religion, foundation, universality, pathos, testimony.

\section{Introducción}

Desde mediados del siglo XIX se registra un notable avance de las ciencias orientadas hacia las religiones positivas: la sociología, la historia y la psicología de la religión, la investigación comparada de las religiones en el marco de la etnología, la exégesis textual, etc. Nuestro saber histórico acerca de las religiones, nuestro conocimiento de los cultos y los ritos, de las leyes sistemáticas que las estructuran y de sus fuentes, pero, sobre todo, nuestro conocimiento exegético y hermenéutico de los textos sagrados se ha multiplicado en los últimos ciento cincuenta años de un modo potencial. Sin embargo, ¿significa ello que todo este cúmulo de datos objetivos nos haya permitido entender qué es esencialmente la religión como tal y qué lo que lleva a todo hombre a plantearse la cuestión religiosa? ¿Ha llegado acaso a su meta la búsqueda por la religión en su verdad, esto es, por aquello que hace que una determinada relación humana sea llamada religiosa, con la multitud de conocimientos histórico-fácticos de los que actualmente disponemos? Conocer la morfología, fuentes, historia, tradiciones y manifestaciones de una o varias religiones e incluso compararlas para determinar los puntos en común no implica en modo alguno haber determinado el significado de la religión en sí misma, ni mucho menos establecer la legitimidad, esto es, determinar aquello que hace que el hombre en tanto tal se encuentre inserto en una relación religiosa. Por ello, con razón, advierte Bernhard Casper que hoy más que nunca es necesario «un nuevo esfuerzo que lleve el pensamiento hasta sus propios límites, una protē episetmēe, que busque elucidar lo que significa la relación religiosa como tal en su originariedad no desfigurada a través del volverse del hombre a sí mismo y a su ser en el mundo, y que, en este sentido, aparte la vista del interés por ser un conocimiento objetivo que pueda servir a uno u otro 
fin» (Casper, 2004, 14). En concordancia con la precedente afirmación de Casper el término «re-ligión» (mejor sería decir «relación religiosa») en el contexto de la expresión «fenomenología de la religión» no tiene aquí ningún sentido institucional o teológico, caracterizado por la proyección y substancialización de convicciones humanas en doctrinas o instituciones que determinan de una vez y para siempre la «verdad» y que, por tanto, paralizan el carácter aconteciente de la revelación. Aquí «religión» mienta algo enteramente diferente, pero que constituye el origen y la legitimación de las distintas religiones positivas. Por «religión» habrá de comprenderse aquí, pues, un acaecimiento correlativo que experimenta renovadamente el existente histórico humano y en el cual se revelan simultáneamente (y en esa revelación se ligan una y otra vez) por un lado el hombre histórico, temporalizándose como «sí-mismo» en su enfrentamiento a lo divino que lo interpela infinita y absolutamente, por otro lo Divino, donándose a sí mismo en las múltiples formas de su interpelación, y, por último, el mundo, recreado y resignificado a partir de este enfrentamiento o encuentro entre el hombre y lo divino. Este modo de abordar el fenómeno religioso presenta la ventaja de hacer posible la apertura de la religión como acontecimiento histórico bumano, por ende, no desde un ficticio sujeto ahistórico y sin perspectiva ${ }^{1}$, sino desde una cierta correlación concreta entre el sí mismo, lo Divino y el mundo que respectivamente acaece de modos diferentes para cada hombre histórico ${ }^{2}$.

\footnotetext{
${ }^{1}$ Hay que tener en cuenta que al acontecimiento correlativo que hace posible la religión yo sólo tengo acceso como sí mismo que está en una relación religiosa de la índole (confesional o no confesional) que fuere. No es posible hablar desde ningún lado ni desde todos los lados. Fenómeno significa la cosa en el cómo de su darse, en cuanto todo lo que se da, se da en una cierta perspectiva y dentro de un horizonte. Si esto es valedero para cualquier fenómeno, por ejemplo, una silla, tanto más para uno tan personal como lo es la religión. Por lo tanto, el autor sólo puede abordar fenomenológicamente el tema, es decir, buscar la esencia o «lo último» a partir de lo cual es pensable toda relación religiosa desde su propio horizonte histórico de comprensión y perspectiva, correlativos ambos al modo mismo en que se le da el fenómeno. Ello implica hacerlo no «en», sino «desde» el horizonte cultural de las grandes tradiciones teístas y, más específicamente, del cristianismo. De allí que, para una perspectiva fenomenológica, no represente problema alguno el abordar el tema desde el horizonte cultural cristiano, pues inevitablemente la búsqueda de las condiciones de posibilidad del darse del fenómeno parte en fenomenología de una experiencia del fenómeno que, como toda experiencia, es escorzada.

${ }^{2}$ La comprensión de la estructura formal última de la relación religiosa como acaecimiento correlativo es esencialmente múltiple en tanto implica la multiplicidad de acaecimientos del «entre» en el que se encuentran Dios o lo Divino en su infinita actividad de donación, el hombre en la constante reconfiguración de su ser como existencia en el mundo y el mundo en constante recreación. Así esta comprensión fundamental de la noción de «religión» nos abre a la diversidad del
} 
Precisamente en función de esta comprensión fundamental de la noción de religión y en el sentido indicado por Bernhard Casper concibo en este trabajo la fenomenología de la religión y su tarea propia, y no como una corriente o método particular de la filosofía de la religión; menos aún si por tal se entiende, como se lo hizo desde la ilustración, una especialidad subsidiaria dentro del canon de asignaturas filosóficas.

Hasta donde mi conocimiento alcanza la fenomenología de la religión reconoce tres modalidades, sino únicas por lo menos paradigmáticas, que implican perspectivas diferentes de acceso a la cuestión religiosa y que se sitúan, por tanto, de manera diferente respecto de la tarea arriba anunciada. A estas tres perspectivas de la fenomenología de la religión las denomino, de modo por cierto esquemático, metodológico-hermenéutica, fundamentativo-trascendental y pático-testimonial. El objetivo de este estudio no es otro que, primeramente, exponer los rasgos metodológicos y las diferencias esenciales de cada una de estas tres perspectivas a través del análisis crítico de modos paradigmáticos suyos. En segundo lugar, mostrar en qué medida de un modo especial que llamamos «disolución» la tercera perspectiva «soluciona» los problemas inherentes a las otras dos, a saber, el de la universalidad de la relación religiosa y el de la legitimidad de la fundamentación de la religión como tal. Como ejemplos de la primera perspectiva tomaremos la intelección de la fenomenología de la religión del destacado especialista R. Schaeffler y el vínculo entre tal fenomenología y la hermenéutica propuesto por P. Ricoeur. Como ejemplo de la segunda, la fundamentación trascendental no metafísica de Dios que recientemente y desde la fenomenología husserliana ha propuesto Klaus Held. La tercera perspectiva ha sido abierta, a mi modo de ver, fundamentalmente por E. Levinas, M. Henry, B. Welte y J. Patocka, pero sus rasgos metodológicos más generales han sido expuestos con notoria claridad por J. L. Marion.

acaecimiento de lo religioso, evidencia la multiplicidad como una característica originaria de tal fenómeno y señala la imposibilidad de circunscribirlo en una confesión determinada. Ello implica, a su vez, una noción positiva y no meramente negativa de tolerancia. 


\section{Primer paradigma: la perspectiva metodológico-hermenéutica}

\subsection{La aplicación metodológica de la fenomenología}

La filosofía de la religión, concebida como filosofía teológica y anclada en lo que Martin Heidegger llamó constitución onto-teo-lógica de la metafísica (Heidegger, 1957, 31-67) parte de la constitución del concepto del fundamento ontológico último de todo lo que es, ya sea el primer motor inmóvil, la causa sui, el Uno-Todo, etc. Luego este concepto filosófico abstracto se identificó con aquello que las religiones efectivamente existentes denominan «Dios». En un tercer paso del concepto abstracto identificado con Dios se derivó el criterio sobre cuya base se podía determinar objetivamente todo discurso acerca de Dios. Y, como advierte R. Schaffler, «recién en un último paso argumentativo fueron consideradas las proposiciones de las religiones efectivas para ser medidas de acuerdo con este criterio» (Schaeffler, 2002, 105).

La fenomenología de la religión, comprendida como método, opera justamente de la manera inversa. Ella parte originariamente de los testimonios y revelaciones positivas de la diversidad de religiones efectivas. En un segundo paso dirige la reflexión a aquello común análogo que funda la comparación entre estas diversas religiones. Se habla entonces de «fenómenos fundamentales» o «estructuras esenciales» de lo religioso. Los diversos fenómenos que se manifiestan en las religiones concretas y empíricas son, pues, analizados y conceptualizados como variaciones de estas estructuras esenciales. Recién entonces y sólo «a veces se plantea la pregunta por cómo Dios puede ser pensado, de modo que pueda hablarse de él tal como el contexto de fenómenos religiosos lo exige»(Schaeffler, 2002, 106.). Si antes la teología filosófica pretendía construir una «religión de la razón», la fenomenología de la religión pretende ahora comprender «la racionalidad de la religión».

Este procedimiento se conjuga con el hecho señalado del notorio aumento de conocimientos objetivos acerca de las religiones efectivas y la dificultad consiguiente para llegar a un concepto de religión que no sea tan estrecho que no pueda explicar múltiples modos de religiosidad efectiva ni tan amplio que sea un mero esquema funcional o formal que pueda dar cabida a fenómenos no religiosos. De esta conjunción resulta la aspiración de los fenomenólogos de la reli- 
gión de aplicar la fenomenología como un método que le permita acceder por medio de la variación eidética a un concepto de religión que no sea ni la mera abstracción surgida de un cúmulo de impresiones obtenidas de distintas apariciones (Erscheinungen) efectivas de lo religioso, ni un huero esquema formal arbitrario que proyecta el investigador para organizar su propio material. Por el contrario, se trataría de conceptos que, desde las apariciones concretas de los fenómenos religiosos, puedan asir la esencia del fenómeno. Lo que no le ha sido posible al procedimiento de la abstracción, debiera serle posible al método fenomenológico, a saber: «captar en aquellos fenómenos religiosos particulares como, por ejemplo, oraciones, sacrificios, formas de constitución de comunidades religiosas, etc. la ley estructural, que posibilita reconocer también en otras religiones expresiones lingüísticas comparables como oraciones, acciones rituales, sacrificios, constitución de comunidades, etc.» (Scheffler, 2002, 109). Además, el concepto fenomenológico de esencia tendría que servir no sólo para posibilitar la comparación entre fenómenos procedentes de religiones y culturas diversas, sino como criterio que permita detectar perturbaciones de las estructuras fundamentales y formas decadentes de lo religioso.

Pero la significación metodológica de la fenomenología para la filosofía de la religión no se agota en la intuición eidética, sino que se asienta, ante todo, en el descubrimiento fenomenológico «de un a priori correlacional universal del objeto de experiencia y de sus modos de donación» (Cortine, 1992, 9.), esto es, de la rigurosa correlación entre el cómo del aparecer de un objeto a la conciencia y el objeto que aparece. Se trata de la famosa correlación entre los actos noéticos y los contenidos noemáticos, que, aunque constituyen realidades de distinta índole, sólo pueden entenderse en su mutua referencia. Esta correlación fundamental de la fenomenología le sirvió al filósofo de la religión para estructurar la relación entre la revelación divina y la fe humana como el modo específico de acceso a la cuestión religiosa. Pues es la convicción del hombre religioso que sólo aquel que ha sido iluminado por Dios, que tiene la gracia de la fe, puede comprender su revelación y percibir su realidad efectiva (Wirklichkeit).

Finalmente, en un tercer sentido, que fundamentalmente ha sido recogido y señalado por Max Scheler, es útil metodológicamente la fenomenología a la filosofía de la religión, a saber: la última saca provecho de la convicción de la primera de que cada región de fenómenos tiene su modo propio y original de evidencia y no se puede pretender que todos los fenómenos sean evidentes del 
mismo modo. Si un fenómeno se presenta de un modo tal que no puede ser objetivado o si es accesible a los sentimientos y no a la razón, ello, para la fenomenología, no representa una manifestación oscura o confusa del fenómeno, sino una característica positiva de su modo de evidencia. «La primera verdad segura de toda fenomenología de la religión es la afirmación de la originalidad y de la irreductibilidad de la experiencia religiosa.» (Scheler, 1965, 257).

Sobre la base de estas tres aplicaciones metodológicas el filósofo de la religión deviene «fenomenólogo» en cuanto llega a una fundamentación de la legitimidad de su propia disciplina a partir de puntos centrales del programa husserliano. La fenomenología de la religión se desarrolla así como una fenomenología regional, sin que por ello sus cultores le adjudiquen carácter normativo al conjunto del programa de Husserl ni se vean comprometidos con todos su puntos y, ante todo, con aquel central que pone entre paréntesis la existencia nouménica o real de lo dado más allá de las vivencias que lo intencionan y constituyen ${ }^{3}$. Aun cuando se acepte que el filósofo de la religión puede aplicar metodológicamente la fenomenología sin comprometerse por entero con todas sus tesis cosa que suscribo - se plantea la cuestión de si esta concepción metodológica responde a la tarea que arriba le adjudicábamos a la fenomenología de la religión, a saber, si puede explicar qué es en sí misma la relación religiosa y si puede ofrecer un fundamento fenomenológico que legitime universalmente dicha relación. Sobre este punto soy escéptico. En mi opinión se ciernen sobre la fenomenología de la religión así concebida tres sospechas.

En primer lugar, la sospecha de la parcialidad o, dicho de modo negativo, de la incapacidad para dar cuenta de una noción esencial y, por tanto, universal de religión. Esa sospecha se sustenta en un círculo hermenéutico, a saber: la aplicación metodológica de la fenomenología en la filosofía de la religión aspira a hacer visible por medio de la comparación entre las diversas formas de aparición de lo religioso la «racionalidad de la religión», esto es, la estructura fundamental o la esencia del fenómeno religioso; aquello universal que estaría presente como el núcleo de toda relación religiosa. Pero ello, como es notorio,

\footnotetext{
${ }^{3}$ Cabría aquí, tal vez, traer a colación la advertencia de Husserl en Ideas I: «Sin haber captado en su carácter propio la actitud trascendental y haberse así apropiado realmente del puro suelo fenomenológico, se puede hacer uso tanto como se quiera de la palabra fenomenología, pero la cosa misma no se la tiene.» (Husserl, 1950, 216).
} 
presupone precisamente esa esencia que se quiere intuir en los fenómenos, en cuanto de antemano ya hay que discriminar entre ellos aquellos que sí son religiosos de otros que no lo son para encontrar luego en los primeros su esencia. La pregunta obvia es: ¿sobre la base de qué criterio discrimino qué es religioso y qué no para luego extraer la esencia de lo religioso de aquello que primeramente de modo arbitrario ya recorté como tal? Surge así la duda de si la aplicación metodológica de la fenomenología a la filosofía de la religión puede poner de manifiesto en realidad qué es la religión en sí misma, cuál es la esencia universal de la religión o tan sólo los rasgos estructurales comunes de un cúmulo de religiones positivas consideradas. Si lo último es el caso, como el mencionado círculo parece indicar, entonces la perspectiva metodológica no habría podido evitar el problema que advertíamos en la introducción: el de la imposibilidad — ni siquiera valiéndose del método fenomenológico, la variación eidética y la fenomenología comparada- de extraer la esencia universal de la religión en tanto relación aconteciente y efectivamente vivida de un conjunto de datos provenientes de las ciencias positivas. Si se considera, como lo hace Schaeffler, la «hierofanía», el modo específico de manifestación de lo sagrado, como objeto de la conciencia religiosa (Schaeffler, 2002, 141), el problema está en determinar de antemano la especificidad de ese modo. Si aceptamos, tomando en consideración el lado noemático de la correlación, que la relación religiosa es una relación con lo sagrado a través de lo cual lo Divino se manifiesta, y si aceptamos también que lo Divino está más allá de todo conocimiento y toda representación (en caso contrario sería un producto idolátrico), debemos concluir que no pueden determinarse a priori las condiciones de su aparición, esto es, aquellos fenómenos que sí son religiosos, que sí son hierofanías, de otros que no lo son. Y si, por otro lado, atendiendo al término noético de la correlación, aceptamos que la relación religiosa es una relación personal, viva y acaeciente con lo sagrado, aunque ella luego se exprese en estructuras interperso-

\footnotetext{
${ }^{4} \mathrm{~B}$. Welte distingue la religión como acontecimiento existencial y como institución objetiva. Nadie dudaría de caracterizar como religioso por su propia esencia e inmediatamente el acontecimiento subjetivo y existencial de la oración en silencio de un hombre de verdadera fe. Pero, por otra parte, también designamos con el término religión un sustrato objetivo dado por un conjunto de textos, ritos, dogmas, cultos, edificios, etc. Ahora bien, a diferencia del primer caso, este sustrato no es por sí mismo e inmediatamente religioso, sino que llega a serlo en tanto y en cuanto por su mediación el acontecimiento religioso existencial se in-stituye en el mundo público como una realidad objetiva. De allí que tal sustrato objetivo sea por naturaleza ambiguo e insuficiente para determinar el ámbito de manifestación de lo sagrado. (Cf. Welte, 2008, 41 ss.).
} 
nales de carácter objetivo (lo que Welte llamaba esfera de mediación) ${ }^{4}$, y si, además, aceptamos que cada persona es absolutamente singular, la conclusión anterior debe reforzarse: considerando la alteridad recíproca de cada relación religiosa personal con lo sagrado en su infinitud inasible no es posible decir qué es religioso o no basándose exclusivamente en sus manifestaciones positivas y objetivas. Pero precisamente éste es el expediente al que acude, por ejemplo, R. Schaeffler que, combinando la fenomenología de la religión con un análisis trascendental del lenguaje, intenta determinar reductivamente lo religioso por medio del análisis trascendental de sus manifestaciones lingüísticas; reducidas éstas a su vez a sus expresiones objetivas o Dichos: cultos, ritos, textos, y, sobre todo, a la tradición interpretativa de estos, es decir, a su historicidad. De este modo —no se sabe por qué— quedan excluidos de lo «genuinamente religioso», la vivencia existencial y personal de contacto con lo Absoluto y los distintos modos que no plasman en la tradición de las religiones históricas constituidas, pero que resultan del encuentro entre lo Divino inobjetivable y la alteridad humana irreductible ${ }^{5}$. Así, la combinación de la analítica trascendental del lenguaje con el método fenomenológico que prometía acceder a una universalidad esencial y no a una mera abstracción en la determinación de lo religioso concluye restringiendo notoriamente esa universalidad y afirma, por ejemplo, que: «los contenidos de la tradición devienen instancias a las que uno puede referirse para determinar el juicio valorativo de expresiones y forma de comportamiento religioso, porque sin estos contenidos tradicionales no está preparado el contexto en el cual la vivencia subjetiva debiera encontrar su sitio, si tiene que ser reconocida en un sentido religioso como válida objetivamente»(Schaeffler, 2002, 300-301). Más allá de la dificultad de entender qué significa «validez objetiva» de una relación entre dos términos n objetivos: lo Divino y el alma humana, esta prefiguración de lo verdaderamente religioso deja abierta la posibilidad de impugnarle ese carácter incluso a las religiones que no aceptan la tradición como fuente de revelación. Así, la filosofía de la religión de Schaeffler queda abierta a la crítica que fue dirigida a su propia Religionsphilosophie y que los Nachträge a

\footnotetext{
${ }^{5}$ En realidad Schaeffler opera una curiosa inversión respecto de la posición de Welte. Si este último sostenía con toda razón que la esfera de mediación, las distintas formas de lenguaje objetivo a través de las cuales se exteriorizaba lo sagrado y se transmitía su revelación, adquirían su sentido religioso por la institución en ellas de la religiosidad como acontecimiento existencial, para Schaeffler la religiosidad como acontecimiento existencial tiene sentido religioso si se instituye en una esfera de mediación objetiva históricamente transmitida y, por tanto, tradicional.
} 
la segunda edición no han podido, a mi modo de ver, disipar del todo. Tal crítica podría perfectamente expresarse con las propias palabras con las que Schaeffler cierra su obra, con la cautela de reemplazar el decidido «no» del autor por el disconforme «sí» del crítico: «Una filosofía de la religión que se sirve a la vez de métodos fenomenológico-trascendentales y del análisis del lenguaje no está [en mi opinión «sí» está A.G.] al servicio del sometimiento de lo sagrado y lo divino a la subjetividad humana.» (Schaeffler, 2002, 318).

Íntimamente vinculada con esta primera sospecha acerca de la incapacidad de acceder a un concepto verdaderamente universal y neutral de religión que no presuponga ninguna teología de una religión determinada, se agrega una segunda que ha formulado explícitamente J. Greisch (Greisch, 2004, 117), recogiendo una expresión del filósofo alemán de la religión Johann Adriansee, a saber: la sospecha de que la aplicación de la fenomenología a la filosofía de la religión no parta en realidad del suelo fenomenológico neutral del que hablaba Husserl, sino que, en realidad, se practica en la mayoría de los casos «desde el cristianismo» («vom Christentum aus»), es decir, que supone la intelección cristiana de la fe y de la revelación. Dicho sintéticamente, a esta perspectiva le cabe la sospecha de ocultar una «teología filosófica», ignorando así que la teología es una función de la religión y que la religión como forma de vida y figura existencial propia es ajena a la filosofía.

Finalmente, y a modo de intensificación de la segunda, está la sospecha «apologética», también señalada por Greisch (Gresich, 2004, 117), a saber: la sospecha de que la fenomenología de la religión ocultamente intenta salvar la racionalidad de pretensiones teológicas y convicciones religiosas por medio de su traspaso al ámbito de la filosofía. Dicho sintéticamente, se cierne aquí sobre la fenomenología de la religión la sospecha de ocultar una «filosofía religiosa».

Puesta en la encrucijada de convertirse o bien en una «teología filosófica»e incluso en una «filosofía religiosa» apologética, o bien de recaer, por un exceso de abstracción, en una concepción metafísica que termine afirmando aquello de lo que partía la «filosofía teológica» de la que intentaba distinguirse: un concepto teológico-natural de Dios, la fenomenología de la religión en su perspectiva metodológica toma conciencia de la necesidad de una mediación hermenéutica, cuyos rasgos fundamentales los ha trazado P. Ricoeur. 


\subsection{La mediación hermenéutica}

A diferencia de la visión puramente metodológica de la fenomenología de la religión aplicada a las manifestaciones religiosas objetivas y como condición para dejar de lado la crítica que formulábamos más arriba acerca del sometimiento de la alteridad divina y humana al poder del sujeto, Ricoeur llama la atención sobre el hecho de que los fenómenos religiosos originarios son «sentimientos absolutos», de los que no se puede dar cuenta a partir del conjunto de relaciones por las cuales la espontaneidad noética del sujeto determina «de un modo objetivamente válido» precisamente sus objetos, incluso los llamados religiosos. «Estos sentimientos consisten en maneras de ser afectados absolutamente, desmintiendo la incapacidad de la fenomenología a abrir la intencionalidad de la conciencia a una alteridad integral.» (Ricoeur, 1992, 16). Ejemplos de estas afecciones absolutas serían la responsabilidad por el otro (Levinas), la vida como autoafectividad (Henry), o el sentirse ya siempre amado y dotado de una confianza originaria en la existencia (Rosenzweig), etc. Ellos tienen en común el hecho de que se trata de afecciones des-mesuradas que no tienen su origen en el sujeto y que éste no puede ni determinar ni evitar. «A estos sentimientos y afecciones absolutas corresponden otras actitudes fundamentales, que se las puede ubicar bajo el título general de oración (...). La oración se dirige activamente a esto Otro por el cual la conciencia está afectada en el plano del sentimiento. Consecuentemente esto Otro que la afecta es percibido como fuente del llamado al cual la oración responde» (Ricoeur, 1992, 16). Ricoeur, a mi modo de ver con total razón, afirma que es posible una fenomenología que describa los rasgos universales propios de la relación entre el llamado y la respuesta, que parece regir en el dominio de estos sentimientos absolutos. Tal fenomenología superaría la dificultad que le opone a la fenomenología de la religión la conciencia intencional, en la medida en que esta última permanecería prisionera de su limitación representativa y llevaría al sujeto a someter lo divino a un producto de la espontaneidad de la conciencia. Y ello porque los sentimientos absolutos evocados implican una pasividad originaria, anárquica, de la que ninguna historicidad puede dar cuenta y que, en tanto tales, testimonian el más allá de la intencionalidad misma.

Sin embargo, Ricoeur, inmediatamente después y en mi opinión innecesariamente, sino contradice, al menos restringe fuertemente la afirmación anterior 
y niega que sea posible tal fenomenología inmediata del testimonio. Ello ocurre en la medida en que, a diferencia de fenomenólogos como Levinas, Henry, Patocka o el propio Welte, Ricoeur sitúa la respuesta al llamado en el plano de la oración concebida como un Dicho lingüístico particular que se concreta en géneros textuales diversos (súplica, petición, alabanza, etc.) y, de ese modo, le niega o le limita severamente a la fenomenología hermenéutica la posibilidad de la descripción y la explicitación de la respuesta que testimonia el llamado en el plano del Decir, esto es, la posibilidad de la descripción y explicitación de la estructura del acaecimiento mismo de fenómenos universales como lo son en principio las afecciones y las actitudes vitales que el llamado genera ${ }^{6}$. Para Ricoeur, para expresarlo de un modo teológico, Dios no le habla al hombre inmediatamente y a cada momento desde dentro de su propia alma, sino sólo a través de la mediación textual. Dios permanecería mudo en las religiones que no lo son del libro. La consecuencia inmediata de esta aparente imposición de Ricoeur de un formato (que ahora no debe acomodarse a la tradición, pero sí a la textualidad) a la revelación divina es la necesidad o la condena que sufre la fenomenología «de pasar por los puntos cardinales de una hermenéutica y más precisamente de una hermenéutica textual o escrituraria» (Ricoeur, 1992, 19). Pero como los textos lo son de una determinada religión positiva o de otra no es posible una fenomenología del «fenómeno religioso tomado en su universalidad indivisible», sino que habría que contentarse «con trazar las grandes líneas hermenéuticas de una sola religión» (Ricoeur, 1992, 20). De esta manera la fenomenología sigue siendo el método correcto de acceso, pero ya no a la religión en general, sino a una religión determinada y mediada siempre y necesariamente por una hermenéutica textual. La perspectiva metodológica deviene metodológico-hermenéutica y se hace cargo, así, explícitamente, de su situación hermenéutica, a saber, el de ser practicada desde una religión determinada, concretamente en el caso de Ricoeur «vom Christentum aus». De este modo la perspectiva fenomenológico-hermenéutica deshace los dos términos del dilema o la encrucijada que señalábamos al fin del apartado anterior. Por un lado, a diferencia de la perspectiva puramente

\footnotetext{
${ }^{6}$ «La dificultad mayor con la cual debe medirse una fenomenología de la religión es de otra naturaleza. Concierne al estatuto de inmediatez que podrían reivindicar las actitudes y los sentimientos solidarios de la estructura llamado y respuesta de orden religioso. Si no hubiera que tener en cuenta la mediación lingüistica, sin la cual sentimientos y actitudes, abandonados al mutismo, permanecerían informes, la dificultad sería menor y no verdaderamente decisiva.» (Ricoeur, 1992, 18. Subrayado mío).
} 
metodológica, la fenomenológico-hermenéutica (el «giro hermenéutico» de la fenomenología de la religión) queda al margen de la sospecha de convertirse en teología filosófica (segunda sospecha) o incluso filosofía religiosa (tercera sospecha), en cuanto su práctica no supone una adhesión existencial a las escrituras judeo-cristianas, sino «una asunción en imaginación y simpatía compatible con el suspenso del compromiso de fe» (Ricoeur, 1992, 20). Por otro lado queda también desactivado el otro riesgo tan cercano a la fenomenología comparada de las religiones, a saber, el de encubrir una teología natural y «llegar» al lugar del cual parte la filosofía teológica, esto es, un concepto puramente abstracto de Dios y de religión. Por el contrario la nueva formulación de esta perspectiva niega «la adopción de un lugar fuera de lugar (...) desde donde el sujeto epistemológico no interesado consideraría con un ojo neutro y simplemente curioso el campo disperso de las creencias religiosas» (Ricoeur, 1992, 21), y se limita, como dijimos, a mantenerse en suspenso fenomenológico respecto de las propias convicciones y a practicar a la vista de las otras religiones «la misma asunción en imaginación y simpatía que exijo a mis auditores cuando procedo ante ellos a la hermenéutica de la fe hebrea y cristiana.» (Ricoeur, 1992, 21).

Ahora bien, la sospecha que no queda desactivada es la primera y el problema con el que se topa esta modificación de la perspectiva metodológica salta a la vista: cómo llegar a una fenomenología universal del fenómeno religioso a partir de la hermenéutica textual de una confesión determinada. La respuesta que da Ricoeur es que sólo es posible llegar a una fenomenología tal en un segundo momento «regido por un procedimiento de transferencia analogizante, conducido paso a paso, a partir del lugar desde el que se tiene el punto de partida» (ricoeur, 1992, 21). La idea de la filosofía de la religión permanecería como una mera idea reguladora, como horizonte último hacia el cual se proyectaría paulatinamente sin llegar nunca «una hospitalidad inter-confesional o inter-religiosa comparable al que preside el trabajo de la traducción de una lengua en otra» (Ricoeur, 1992, 21). Más allá del detalle de que Ricoeur ponga como sinónimos los términos «confesional» y «religioso», negando así el fenómeno fácticamente dado y característico de nuestros tiempos de modalidades religiosas no confesionales, que, por supuesto, tampoco serían abrazadas por el horizonte ideal de una filosofía de la religión, no queda clara cuál sería la esencia de la «transferencia analógica» que nos permite avanzar paso a paso y de religión en religión. Esto es, no queda claro cómo y sobre la base de que horizonte — si queda excluida metodológicamente una hermenéutica de la factici- 
dad, es decir, del acaecimiento de las afecciones que testimonian la multiplicidad de formas del llamado de lo Absoluto- podría constituirse y operar esta analogía. Y no parece que la mera «asunción en imaginación y simpatía» de las otras escrituras y la consecuente «hospitalidad inter-confesional» sea condición suficiente para determinar de modo concreto el horizonte dentro del cual operaría la transferencia. De hecho el propio Ricoeur reconoce esta dificultad no menor cuando afirma que el problema que queda abierto «es el de saber cómo esta conciencia religiosa, formada por el Gran Código bíblico podría abrirse a otras conciencias religiosas, formadas por otros códigos escriturarios y cómo ella podría comunicarse con aquellas bajo el horizonte de la idea reguladora evocada (...) bajo el título de hospitalidad inter-confesional entre religión y religión». (Ricoeur, 1992, 37-38).

En conclusión la mediación hermenéutica de la aplicación metodológica de la fenomenología no logra resolver el problema de la significación universal de la relación religiosa, en cuanto supedita la tarea de la fenomenología a las mediaciones lingüísticas particulares. Sin embargo, no termina de quedar claro por qué la fenomenología no accedería a la relación religiosa en el plano del Decir, esto es, a través de la descripción fenomenológica y explicitación hermenéutica de la facticidad $^{7}$ de los acaecimientos en los que se da de modo testimonial el llamado de lo Absoluto, ni por qué deba necesariamente toda respuesta a ese llamado encarnarse textualmente y darse en el marco de las religiones escriturarias. Ciertamente la Escritura y su solicitud de una interpretación infinita, esto es, el hecho de que en ella el «poder decir» supera el «querer decir», puede ser tomado como uno de los modos de apelación de lo Absoluto, pero no se entiende por qué debería ser el único. La afirmación de Ricoeur de que sentimientos religiosos o, por lo menos, sentimientos que responden a una afección absoluta «no se muestran en ninguna parte en su inmediatez desnuda» (Ricoeur, 1992, 19), es acep-

\footnotetext{
${ }^{7}$ Aquí entendemos, pues, hermenéutica no en el sentido de una interpretación de textos fundada en la consideración de los géneros literarios o las diferentes tipologías propias de la Biblia o cualquier otro texto sagrado y sus reglas morfológicas y semánticas intrínsecas, sino en el preciso sentido que Heidegger, remitiéndose a la significación originaria, le otorga, a saber: el de «autoexplicitación de la facticidad». De cara a su objeto, la hermenéutica tiene como su tarea propia y esencial, el comunicar, volver accesible o patente el respectivo cómo o modo de darse del fenómeno, en cuanto tal fenómeno, por su mismo modo de acaecer, requiere explicitación para llegar a ser comprensible, en este caso la explicitación de su condición de testimonio de lo absoluto. Al respecto, Cf. Heidegger, 1995, 9; 14-16.
} 
table en cuanto esos sentimientos se manifiestan o testimonian en las actitudes vitales o las respuestas que generan. Pero la consecuente afirmación de que «se muestran ya siempre interpretados según reglas canónicas de lectura y escritura» (Ricoeur, 1992, 19) es, sino una petición de principios, al menos una limitación a priori de esos sentimientos y las actitudes que generan, la cual excluye toda forma de religión y religiosidad no escrituraria y restringe incluso las religiones positivas a las religiones del libro. También es cuestionable la conclusión a la que llega Ricoeur, a saber: que si la fenomenología se obstina en poner al desnudo la estructura de la relación apelación-respuesta, por ejemplo, a través de lo que hemos llamado fenomenología testimonial aliada con una hermenéutica de la facticidad, «no tardaría en percibir que es cada vez de manera diferente y con una significación diferente que es experimentada y practicada (...) la obediencia a la Altura» (Ricoeur, 1992,19). La cuestión radica precisamente en si es legítimo calificar a las maneras diferentes en que se experimenta y practica la obediencia a la Altura fuera de las religiones textuales como un «mutismo ciego» o insensato, o de si, por el contrario, la multiplicidad de formas en que acontece la estructura llamado-respuesta dentro y fuera de los cánones escriturarios (y que ocupa pensamientos diferentes como el de Levinas, Henry, Welte o Patocka, para citar sólo algunos) en realidad es el testimonio más claro de la riqueza y la diversidad infinita del llamado, que refleja, a su vez, la excedencia infinita de lo divino y sus dones. La mediación hermenéutica parece haber desatendido la certera advertencia que hace $\mathrm{M}$. Henry refiriéndose a la imposibilidad de reducir la revelación, que acontece en la vida, a las solas Escrituras, a saber: «La emoción que vincula al viviente con la Vida eterna [con lo Absoluto o la Altura AG] va más allá de toda forma de cultura del orden que ella fuera. Ella nace y puede nacer de [múltiples modos AG] de la vida misma como este renacimiento que le permite experimentar una y otra vez su nacimiento eterno. El espíritu sopla de donde quiere.» (Henry, 1992, 160).

\section{Segunda perspectiva: el paradigma de la fundamentación trascendental}

\section{1. ¿Dios ideal o Dios finito?}

De igual modo que el primer paradigma, el de la fundamentación trascendental intenta apartarse de la filosofía teológica y de su anclaje en la constitu- 
ción ontoteológica de la metafísica, pero, a diferencia de aquel, no tiene como su objeto las religiones positivas, ni para determinar su esencia por medio del análisis fenomenológico comparativo, ni para proyectarlas sobre el horizonte ideal de la religión sobre la base de una transferencia analogizante resultante de la hermenéutica textual. Su objeto es otro, a saber: fundamentar de modo no metafísico y a partir de los principios de la fenomenología husserliana un concepto de Dios que pueda eventualmente servir como el núcleo racional al que debieran remitirse todas las religiones y figuras no idolátricas de la divinidad. Este modelo ha encontrado recientemente una expresión notable en un trabajo del prestigioso fenomenólogo Klaus Held acerca de la «fundamentación fenomenológica de una comprensión no metafísica de Dios» (Held, 2009, 9) dos principios husserlianos básicos. En primer lugar, asume que su análisis presupone la reducción trascendental y la consecuente epojé, lo que le permite instalarse en una actitud neutral y hablar sobre lo divino, absteniéndose simultáneamente de cualquier juicio acerca de la existencia o no de su objeto de referencia. En segundo lugar, supone la exigencia de evidencia como última fuente de la legitimidad del conocimiento. Por tal habrá que entender el hecho de que la comprensión de una cosa nos remita a un encuentro con ella en la que ésta se nos dé por sí misma de modo inmediato y no desfigurado. De acuerdo con esta última convicción el origen del cual emerge el proceso husserliano de constitución de la significación de una cosa es su auto-donación. Ahora bien, no basta con la evidencia, que es condición necesaria pero no suficiente, para que este proceso se desencadene, sino que, además, son necesarios fundamentos que nos muevan a desencadenarlo. Se trata de fundamentos motivacionales (Bewegungsgründe) que determinan nuestro comportamiento y las cosas de las que nos ocupamos en el mundo de la vida con anterioridad a toda filosofía. Una fenomenología, sostiene Held, que quiera verse desde el punto de vista metodológico libre de prejuicios no puede pasar por alto la necesidad de estos fundamentos.

A partir de esta posición metodológica y asumiendo que el término «lo divino» funcione como expresión que unifica de modo meramente lingüístico y no en lo atinente a la significación objetiva de la cosa misma (sacblicb) las distintas figuras mono- y politeístas de la divinidad, Held presupone que «se debe dejar encontrar una motivación unitaria a partir de la cual nuestra relación con lo divino pueda fundamentalmente ser aclarada» (Held, 2009, 11). Y se pregunta: «¿Hay una tal motivación?» (Held, 2009, 11). La palabra clave, que Held toma de Hus- 
serl, para la respuesta a esta pregunta es «poderes» (Vermöglichkeiten) ${ }^{8}$. Lo divino en cualquiera de sus figuras está provisto de poderes sobrehumanos. «La motivación unitaria para la constitución de una unidad objetiva [y no meramente lingüística AG] de significación de lo divino es nuestra experiencia de una insuperable carencia de poderes, (...), dicho brevemente, la experiencia de nuestra humana impotencia» (Held, 2009, 11). El fundamento motivacional para la constitución (en estricto sentido fenomenológico) de la noción de lo Divino sería, entonces, la finitud humana y la sobre-potencia divina. Sin embargo, hay que tener en cuenta que, si este poderío divino resultase de la potenciación de poderes meramente humanos, si viniese a completar los poderes que no hemos sido capaces de desarrollar, si viniese, por ejemplo, a traer justicia a un mundo que no ha sabido, pero que, en principio, podría darse mejores sistemas de justicia, este Dios sería un ídolo y el proceso de constitución una mera proyección de las necesidades humanas no satisfechas, como lo ha advertido desde siempre la crítica de la religión. Esta comprensión idolátrica sería, para Held, el plano en el que se ubican las religiones politeístas de los pueblos originarios, cuya divinidades resultan de la potenciación o incremento de poderes meramente humanos: la fuerza física, la fertilidad, etc. ¿Cuál es, entonces, un poder que le está por completo vedado al hombre y que sólo una divinidad podría poseer? Extrañamente Held encuentra este poder no en la inmortalidad ni en la bondad absoluta ${ }^{9}$, no en el amor ni en la capacidad creadora de vida; no lo encuentra en ninguna de todas aquellas cuestiones existenciales cruciales que remitieron al hombre a relacionarse en el mundo de la vida con lo divino, sino que reconoce el buscado fundamento motivacional en el poder que tendría lo divino de percibir un objeto desde todas las perspectivas. En efecto, toda percepción humana de una cosa se desarrolla siempre desde una determinada perspectiva, dada por la posición del cuerpo propio; y no se da aislada, sino que está referida a una serie de aparicio-

${ }^{8}$ Vermögen mienta originariamente en alemán el conjunto de las posesiones materiales de las que alguien dispone y, de modo figurado, los poderes que ellas le permiten ejercer. El neologismo husserliano Vermöglichkeiten (literalmente «poderialidades» mienta pues las potencialidades, en este caso de lo divino, pero no en el sentido de posibilidades en tanto tales, sino de poderes reales y efectivos. La palabra potencialidad está en español demasiado cerca de mera posibilidad y no de posesión del poder, por eso he elegido el término «poderes».

${ }_{9}^{9}$ En este aspecto quisiera volver a Kant en contra de Held y recordar que una buena voluntad absoluta no contaminada de ningún egoísmo no es la exacerbación de un poderío humano, de una cualidad que un hombre pudiese tener idealmente, sino que la bondad absoluta es imposible por nuestra propia constitución como seres finitos. 
nes parciales del objeto (escorzos) que resultan de la relación entre la impresión actual, la retención de impresiones de las fases pasadas del objeto y la protención de las impresiones esperadas y prefiguradas de las fases siguientes de ese mismo objeto. El conjunto o serie puede verse confirmado cuando las impresiones protendidas y prefiguradas se ven plenificadas con las nuevas impresiones y el objeto es así afirmado; o puede también verse decepcionado cuando la serie de impresiones no son concordantes. Pero al hombre le es absolutamente imposible percibir a un tiempo el objeto desde todas las perspectivas, por lo que la aspiración humana a una concordancia absoluta de sus percepciones que garantice el conocimiento y el obrar no es posible. Y ello por dos razones: porque nuestras percepciones y nuestro obrar están ya siempre referidos a prefiguraciones proyectadas hacia el futuro, y porque no podemos conocer cuáles son las percepciones ni cómo será el consecuente obrar de los otros. Pero el hombre — afirma Held - para poder actuar necesita precisamente confiar en dos cosas. Primero que sus protenciones del futuro tengan un mínimo contenido de realidad y converjan con sus impresiones actuales y sus retenciones pasadas. Segundo: yo debo suponer un cierto grado de previsibilidad en el obrar del otro y confiar en que sus impresiones del mundo guardan una cierta convergencia con las mías. El sentido de cualquier relación o comportamiento que tenga respecto de algo y, de ese modo, el sentido de mi vida entera, depende de que esté fundamentada la confianza en poder evitar estos dos modos potenciales de conflicto: el temporal y el intersubjetivo. Sin embargo, el hombre, remitido a sí mismo, nunca puede tener certeza teórica en esta confianza que prácticamente supone, por el mencionado carácter subjetivo y temporalmente limitado de su perspectiva perceptiva. «Así sólo queda la posibilidad, la instancia, de buscar en un poderío por antonomasia superior al humano, esto es, en lo divino, la justificación de la confianza originaria» Y prosigue Held: «Con ello ha sido encontrada una motivación para la constitución de lo divino que responde a los criterios metodológicos arriba anunciados». (Held, 2009, 17). En estricta adherencia a Husserl Held llega a la siguiente conclusión: la estructura perspectivística de la percepción funda (en el sentido de que ofrece el fundamento motivacional) con independencia de cualquier posición metafísica una comprensión de Dios que no implica ningún sentido ético, ni relativo a la salvación personal, sino que Dios aparece como última instancia o garante de nuestra confianza en la coherencia gnoseológica del universo. Dios es así el Bien en el sentido originario platónico de lo que hace apto a algo para ser lo que es, de lo que da la garantía para otra cosa. Dios es, además, uno —el Bien uno o único_- puesto que la idea de diversos garantes 
en conflicto unos con otros contradice el fundamento motivacional de la misma comprensión de Dios. «Por ello debe la bondad divina ser una y única» (Held, 2009, 18). De las divinidades politeístas idolátricas el hombre puede hacerse una imagen objetiva y adjudicarles por contraste en grado sumo todos los poderes que encuentra en él mismo en menor grado. El Bien uno, en cambio, no tiene carácter objetivo. Es el garante de toda objetividad, pero la trasciende y encuentra al hombre de un modo enteramente distinto del saber objetivo, precisamente - -y aquí de nuevo se reconoce la estructura de una afección absoluta, respecto de la cual la propia intencionalidad resulta pasiva - en la confianza originaria en que la superación del conflicto entre perspectivas no es una ilusión; o, para decirlo en otros términos, en la confianza en la coherencia y el sentido del universo. A esta confianza que no se funda en ningún saber y que sólo puede ser legítima si no se refiere a ningún horizonte particular, sino al universo como totalidad de todos los horizontes, es a lo que Held llama «fe». Este Bien único, objeto de una fe racional, es a su vez el télos al que apunta la humanidad toda, pues la idea misma de la humanidad reunida en un mundo debe ser acompañada del crecimiento de la fe en Dios como el Bien uno, pues sólo tal Dios puede garantizar la confianza en el imperio de la concordancia de todos los hombres en el horizonte universal del mundo.

Sin embargo esta concepción de Dios como télos universal queda inmediatamente restringida para Held al rango de un principio ideal inalcanzable, pues asume como propia e ineludible la convicción expresada por Husserl en un célebre pasaje de Ideas I (Husserl, 1950, 351) en el cual se afirma que ni siquiera Dios podría verse desligado de la perspectividad y que un Dios que pudiera percibir las cosas desde todas los puntos de vista y desde todas las conciencias es impensable. Ante esta situación, que conmueve todo el proceso de fundamentación de una comprensión racional de Dios, Held se encuentra ante la siguiente alternativa: o bien tomar el camino de Husserl y caracterizar al télos de la teleología como un polo meramente ideal y pensado al cual la evolución —léase idealizaciónde las religiones se acerca sin alcanzar jamás, o bien tiene que asumirse que un Dios real sólo puede ser finito. Held somete a crítica el primer término de la alternativa. Un Dios como télos ideal, precisamente por la imposibilidad que se dé realmente y por ser sólo un polo pensable, no puede ser objeto de una praxis religiosa concreta de veneración o culto, pues ésta necesita ser plenificada a través de evidencias intuitivas, esto es, de experiencias de una auto-donación (o dicho teológicamente revelación) propia de lo Divino, por ejemplo, en la fiesta, 
los ritos, el sacrificio, etc. «Con la interpretación de la historia de las religiones como proceso de idealización le priva Husserl a la misma fe religiosa de la que habla de su suelo intuitivo. Así se vuelve necesaria para su fenomenología de la religión una auto-aplicación de la crítica que él dirige al olvido del mundo de la vida en la época actual.» (Held, 2009, 26). Dicho de modo tal vez más contundente: si el garante es una mera idea abstracta, se pierde toda confianza en él y, con ello, todo fundamento motivacional que ancla precisamente en el mundo de la vida. Con ello el edificio entero de la fundamentación comienza a tambalear. La conclusión es clara: Dios como valor límite superlativo de un proceso de idealización no puede ser concretamente intuido, ni ser objeto de culto, ni ser la referencia real a la que apunten como fin último todas las religiones, sino que puede ser tan sólo la proyección de una idea humana como garante de las necesidades de la conciencia, ya no moral, sino intencional. La fenomenología habría desembocado de nuevo en una noción abstracta meramente ideal, sin evidencia alguna, como aquella de la «causa sui» de la ontoteología.

Ante tal circunstancia no le queda a Held otra opción que volcarse al otro término de la alternativa y afirmar un Dios finito, cuya superioridad respecto de los poderes humanos sea meramente comparativa y no superlativa. Escribe el autor:

El Dios uno debiera ciertamente, porque él es el Bien o lo Bueno, ser comprendido como instancia garantizadora, que superaría en poder a las múltiples divinidades de las religiones ingenuas de los pueblos originarios y a la que por ello se le podría dispensar una confianza creyente mayor de la que se tendría en tales divinidades. Pero este Dios no debería ser concebido como un superlativo que está al final de un proceso de idealización y con ello pierde su concreta experimentabilidad en el mundo de la vida. (Held, 2009, 26).

Más ello implica que «a este Dios no se le podría simplemente atribuir el poder ilimitado que en la tradición metafísica cristiana se le atribuye al Dios uno» (Held, 2009, 26). Finalmente hay que decir que, según Held, la introducción de esta concepción del Bien, que sí se dejaría experimentar en la intuición como término comparativamente más poderoso que las deidades politeístas, pero cuyo poder es sin embargo finito, en lugar del Dios omnipotente como superlativo de un proceso de idealización representa una contribución respecto del proble- 
ma de la teodicea. Tal problema no es otro que el siguiente: ¿cómo puede conciliarse la idea de un Dios omnipotente, garante de una convergencia absoluta de todos los escorzos y del entero sentido del universo con las catástrofes naturales, la muerte, el sufrimiento la injusticia y el mal? Este problema se plantea solamente si le adjudicamos a Dios una medida infinita de bondad, de poder y de saber, en cuanto su determinación se funda en una idealización. Pero un Dios que trascendiese la potencialidad del hombre aunque fuese finito a su modo (sin que quede muy claro cuál es este modo) no necesitaría una justificación enfrente del mal que, sin dudas, impera en el mundo. La cuestión aquí no es sólo la señalada por Held, a saber, hasta qué punto este Dios finito es compatible con la experiencia y la teología cristiana, sino hasta qué punto es compatible con su propia e inicial concepción de Dios. En efecto, al adjudicarles a los dioses politeístas el rango de meras intensificaciones de poderes en principio propios del hombre y luego determinar la finitud del Dios fenomenológico como comparativamente más poderoso que las deidades paganas, lo deja sujeto a la misma concepción de ídolo de aquellos. El fundamento motivacional se derrumba. Y si la comparación no lo es respecto de los dioses, del hombre o del mundo no se sabe respecto de quién o qué el Dios finito es comparativamente más poderoso.

\subsection{Valoración crítica}

El intento de fundamentar fenomenológicamente una cierta y única comprensión de Dios por la que debieran regularse todas las otras, debido a la propia estructura correlacional del pensamiento fenomenológico, implica, a su vez, la necesidad de determinar unívocamente la aparición de Dios y, en última instancia, determinar su ser, sus posibilidades y hasta el grado de sus poderes. Tal intento resulta desproporcionado, ajeno a toda experiencia efectiva de las religiones positivas, que colocan a Dios más allá de lo pensable y determinable, y termina recayendo en la crítica dirigida al modelo anterior, a saber: supeditar a Dios a la estructura de la intencionalidad perceptiva y, así, al propio sujeto. Esta crítica se agudiza en cuanto este presunto Dios, garante del conocimiento en función de su multiperspectividad, termina siendo una construcción intelectual, un supuesto, que no se revela ni se experimenta fácticamente en sitio alguno. Esta crítica general es notoriamente aplicable al pensamiento de Held si nos atenemos a su propio punto de partida: el fundamento motivacional por el cual nos relaciona- 
mos con lo divino. En efecto, aunque es coherente con el concepto de un Dios suprapoderoso que sea omnisciente y conozca o perciba los objetos desde todas las perspectivas posibles, empero afirmar que éste sea el único poder vedado al hombre y la única razón por la cual éste se relacionaría por lo divino, implica desconocer que ni aún en principio el hombre no puede no sólo no conocerlo todo, sino tampoco amarlo todo, crearlo todo, redimirlo todo y que, antes que cualquier otra cosa, no puede no morir. Implica reducir al conocimiento todos los modos concretos del ser en el mundo con los otros desde los cuales el hombre puede relacionarse con lo divino. Por ello mismo colocar como fundamento iprecisamente motivacional! el no poder no percibir un objeto de todas las perspectivas para conocerlo absolutamente resulta disociado no sólo de las religiones fácticas, sino que no se condice con las motivaciones «del mundo de la vida» que nos llevan a relacionarnos con lo Divino, antes que como garante del conocimiento, como garante del bien, la salvación y de esa vida, que no es sólo conocimiento. Held afirma que únicamente una fenomenología que tenga en cuenta estos fundamentos motivacionales dados por la perspectiva estaría libre de prejuicios y remitida a la evidencia. De mi parte opino que reducir la imposibilidad humana radicalmente diferente de la divina a una cuestión gnoseológica de perspectiva y luego darla como fundamento motivacional no es evidencia ninguna, y menos la única evidencia posible, sino que resulta precisamente de un prejuicio surgido de no ponerse — cosa por lo demás imposible — en una actitud absolutamente neutral, sino en la perspectiva y el interés del sujeto teórico-cognoscente desligado del mundo de la vida. Precisamente por ello, por la necesidad de arraigar su Dios en la intuición, el autor termina no siendo coherente con su propio punto de partida. En efecto, al principio de su trabajo (Held, 2009 , 12) Held niega que cosas tales como la justicia (y podría agregarse aquí también el amor en el sentido ético de ágape y de piedad hacia toda vida finita) implicasen poderes que distinguiesen a lo Divino esencialmente de lo humano, ya que, por ejemplo, por medio de un «esfuerzo ético (ethische Anstrengung)» podríamos llegar a una sociedad perfectamente justa. Sin embargo, al final termina caracterizando implícitamente a su Dios fenomenológico por aquellas propiedades que ha negado como los fundamentos que nos llevan a relacionarnos con un Dios no idolátrico, tales como la justicia y la compasión. Ello es particularmente claro cuando se advierte el problema de la teodicea, a saber, que no se puede compatibilizar la idea de un Dios infinito con las de la desgracia, la muerte y la injusticia que implican, por ejemplo, las catástrofes naturales. En realidad sí pueden compatibilizarse, si a Dios el amor a la vida, la compasión y la justicia 
no le importasen nada, porque perfectamente es pensable que un Dios que ve todo desde todos los puntos de vista, sepa que lo convergente es precisamente tal catástrofe, aunque ella sea padecida con dolor y muerte por los hombres.

Una segunda crítica que hay que dirigir al intento de Held es la de pretender «fundamentar racionalmente» la necesidad de un Dios finito a través de un temple como la confianza. En efecto, la confianza de la que habla Held, en última instancia la confianza en que el universo guarda algún sentido, que la muerte, el caos y la nada no es el destino final de todo; la confianza, en una palabra, en un sentido integral de la existencia humana, no es irracional, pero tampoco es un saber racional. En la vida fáctica no necesitamos saber que el horizonte último de todo lo que se da es convergente, sólo necesitamos confiar en ello. Ahora bien, tenemos que reconocer que no hay ninguna certeza cognitiva resultante de percepciones evidentes que fundamente racionalmente esa confianza, y que, por lo tanto, esa confianza no es racional, sino que es una mera afección cuyo origen es imposible de hallar, una afección an-árquica: lo que antes llamamos el sentimiento de estar concernido por algo Absoluto. Suponer que se podría fundamentar esa confianza introduciendo un polo ideal superlativo de la estructura de la intencionalidad o un término comparativo superior como su garante no es remitirse a ninguna evidencia, sino construir a priori un nuevo concepto abstracto de Dios, y luego querer fundamentar un sentimiento en una abstracción. Que ese concepto no funda racionalmente la confianza queda claro por el simple hecho de que la sospecha de la posibilidad del sinsentido final de todo no puede ser suprimida y, por ello, la presunta garantía que ofrecería Dios, estricta y racionalmente hablando, no es garantía ninguna. Si Dios está fundamentado racionalmente, si la confianza racional surge de una evidencia y no de una construcción, no cabría lugar para la sospecha. Pero existencialmente la sospecha sigue allí y tenemos que actuar y convivir con ella. El problema metodológico de fondo esta aquí en la incompatibilidad entre la única verdadera evidencia situada en el mundo de la vida que puede apuntar Held: la confianza originaria en el sentido de la vida y del universo, y el término «fundamentación». Tal confianza originaria resulta de una afección absoluta que, como tal, se inserta en lo que hemos llamado la estructura interpelación-respuesta, y sobre la cual no es posible fundamentación alguna surgida de la intencionalidad del yo. En efecto, sobre algo fundamentado no se puede dudar, pero la confianza, tal cual lo muestra la inevitabilidad de la sospecha, incluye necesariamente la duda. Como señala con acierto Peter Trawny en su comentario crítico al artículo de Held que «confianza es un apar- 
tarse constantemente de la desconfianza, con lo cual ésta no puede ser aniquilada de un modo absoluto, sino que permanece presente como posibilidad. Si éste no fuera el caso, sería toda forma de súplica y agradecimiento un mero floreo retórico» (Trawny, 2009, 131). Toda verdadera confianza es una confianza más allá de la razón y de las evidencias intencionales. Pertenece al reino de la afectividad y no de la racionalidad cognitiva. «Ella surge de una experiencia fáctica de la vida, en la cual la luz de la razón no puede afirmar ninguna función de fundamentación última» (Trawny, 2009, 130).

Al final del análisis de estos dos modelos de aplicación de la fenomenología a la filosofía de la religión nos encontramos con que ellos no sólo no pueden decirnos qué es en sí misma la religión, que es lo que lleva al hombre a entrar en la relación religiosa, sino que no pueden cumplir la propia tarea que se han propuesto: ni describir la esencia universal de la religión, ni fundamentar el concepto de Dios y la racionalidad de la relación religiosa.

\section{Tercer paradigma: la perspectiva pático-testimonial}

Luego del análisis crítico de los dos paradigmas precedentes tenemos que plantearnos con J. L. Marion la siguiente pregunta: «¿Puede la fenomenología en un sentido privilegiado constituir un aporte al desarrollo de lo que llamamos filosofía de la religión?» (Marion, 2007, 15). Si la respuesta a esta pregunta ha de ser positiva, entonces tienen que darse, como señala Marion (Marion, 2007, 16), dos exigencias. En primer lugar, la religión debe poder legitimarse ante la fenomenología a partir de fenómenos evidentes, «de las cosas mismas». Segundo: la fenomenología debe poder legitimarse ante la religión como un método adecuado para captarla en su origen último y esencia. Para que ello ocurra debe explicitarse en qué medida los conceptos y el método fenomenológico pueden aplicarse al fenómeno religioso sin desvirtuarlo. Ambas exigencias de legitimación implican, en última instancia, afrontar la cuestión de la compatibilidad entre la vivencia de una revelación de lo divino que no puede ser constatada en una evidencia objetiva y la exigencia fenomenológica de evidencias. En efecto, por un lado la religión sólo puede justificarse a sí misma e ir más allá de la adoración idolátrica de fetiches, si ella se remite de un modo u otro a una revelación de lo divino. Pero, por otro lado esta revelación implica la paradoja de una instancia divina que, estando más allá de las condiciones de posibilidad del objeto de la 
experiencia y, por tanto, de la experiencia misma, se vuelve, sin embargo, de algún modo, experimentable.

La fenomenología sólo puede superar esta dificultad si ella misma deviene fenomenología testimonial, esto es, si deviene una fenomenología de lo «invisible». En un célebre pasaje de Ser y tiempo declara Heidegger: «Precisamente porque los fenómenos por lo pronto y las más de las veces no están dados es necesaria la fenomenología» (Heidegger, 1977, 48). De este modo Heidegger advierte la necesidad de incluir en la condición de fenómenos lo que se anuncia sin ser él mismo visible, como, por ejemplo, la nada que se manifiesta en la angustia, o la conciencia que lo hace en el ser-culpable del Dasein. El testimonio es precisamente lo que anuncia un término que no se deja experimentar más que por su efectividad. Todo lo que se anuncia a través de testimonios, en la medida en que el mostrarse a sí mismo por medio de lo que lo anuncia se cumple desde sí mismo, debe, pues, integrarse en el ámbito de lo fenoménico. En consecuencia, queda legitimada en términos generales la posibilidad de una fenomenología de lo no-aparente. De este modo también la religión queda en principio legitimada ante la fenomenología. «Las vivencias de la llamada conciencia religiosa dan acceso intuitivo, pero de modo indirecto a través de anuncios, a objetos intencionales invisibles. La religión deviene manifiesta y la revelación fenomenal.» (Marion, 2007, 24).

¿Pero - y pasamos a la segunda de las dos exigencias que señalamos al principio- puede, a su vez, la fenomenología justificarse no sólo ante la religión como un método propio dotado de una conceptualidad adecuada para acceder a lo divino sin desvirtuarlo? ¿No implica la comprensión y conceptualización fenomenológica de la revelación de lo divino una constitución y una objetivación que degradan lo divino supeditándolo a la intencionalidad? Aquí la fenomenología encuentra sus dos principales obstáculos para legitimarse en dos de sus conceptos más caros: el de yo y el de horizonte. En lo que al primero respecta hay que tener en cuenta que para la fenomenología todo fenómeno resulta de la correlación entre la aparición a la conciencia de un algo y la constitución de la conciencia o «yo» del sentido de ese algo. De acuerdo con ello la captación fenomenológica de la manifestación de lo divino, queda, si no negada, reducida a la estructura de la intencionalidad del yo y, por tanto, desvirtuada como revelación religiosa. Es precisamente este concepto de yo el que operaba notoriamente en el modelo fundamentativo de Klaus Held que, para poder fundamentar lo divino en evidencias, terminaba supeditando la manifestación y las 
características de Dios a las potencialidades e impotencias de la intencionalidad subjetiva y, consecuentemente, construía un concepto de Dios sin asidero en revelación alguna. El segundo obstáculo surge, decíamos, del concepto de horizonte. Todo lo que aparece a la conciencia aparece para la fenomenología en un horizonte que establece las condiciones de posibilidad de la aparición. De allí que la idea de un Dios trascendente y verdaderamente divino, que pueda revelarse por sí mismo más allá de todo horizonte de comprensión parece incompatible con el análisis fenomenológico y la exigencia de evidencia. Es precisamente este concepto de horizonte el que operaba en el primer modelo analizado, cuando se determinaba a priori como horizonte de comprensibilidad de toda revelación la tradición o el código escriturario y, de esta manera, se le ponía límites a lo que por definición no acepta límites: la espontaneidad divina de la revelación. Estas dos dificultades implícitas en el concepto de yo y en el de horizonte expresan el problema que afronta la fenomenología para acceder a la revelación de lo divino, sin que este acceso mismo desvirtúe la revelación supeditándola a la intencionalidad del yo o al horizonte de aparición.

La tradicional determinación husserliana del yo a partir de la conciencia intencional constitutiva ha sido seriamente puesta en duda por nuevas corrientes provenientes de la fenomenología misma, lo que trajo aparejada una «inversión de la intencionalidad»: la subjetividad, concretamente a través del ejercicio de la actividad intencional, ya no es el origen del sentido, sino que el sentido de la subjetividad tiene su origen en la pasividad o pathos de una afección o interpelación que precede a toda actividad intencional. Las diferentes dimensiones de la existencia son vistas como respuesta a una interpelación originaria y ab-soluta respecto de todo poder del sujeto. De este modo, aunque de una forma enteramente nueva, la fenomenología se reencuentra con la vieja convicción eckhartiana de que el sujeto «lleva a Dios dentro de su propia alma» y la subjetividad misma, de maneras diferentes y por medio de distintas dimensiones de la existencia, se convierte en el anuncio o testimonio de esa interpelación absoluta en la que se reconoce la ligazón originaria del sujeto con lo divino. En las múltiples formas que asume, según cada fenomenólogo, la respuesta a ese llamado en el existir concreto, el sujeto se re-liga con lo Absoluto y la religión, antes y como condición de su objetivación en instituciones, cultos, ritos, libros, etc., se da como el acaecimiento de una afección que se testimonia en la respuesta que ella pro-duce. Concebida de tal forma, la subjetividad ya no pone en riesgo el carácter absoluto de la revelación, en cuanto el llamado resuena en la respuesta, sin que la respuesta que expre- 
sa esa afección pueda determinar al llamado. Por el contrario, es el llamado o la afección la que determina el sentido de la respuesta. Este esquema se repite con variantes en diversos fenomenólogos. En Henry la subjetividad, viviendo, se descubre a sí misma entregada a la condición de sentirse a sí misma sin ser ella el origen de esa condición. Dios se revela en la vida, en el hecho de que la vida como experiencia patética de sí, sólo remite a su propia dación, y es, así, algo Absoluto. En Levinas, la subjetividad es un «término de recurrencia», una «subjetividad asignada», que lleva en sí a pesar suyo, cual si estuviese inspirada, la susceptibilidad ante el otro y la consecuente responsabilidad infinita por todo y por todos. En Welte el sujeto no puede para existir sino postular que la existencia en su conjunto tiene sentido, y es precisamente en esa postulación de sentido, que no surge de ningún argumento sino de un pathos, y a partir del cual la existencia es posible, donde se anuncia lo Absoluto. En Patocka, lo Absoluto se manifiesta en el sentir-se llamado el sujeto por una alteridad extratemporal a proyectar en el tiempo libremente nuevas formas del mundo y, de ese modo, a dejar que el ser acaezca y la vida se renueve y asuma configuraciones cada vez más plenas. Incluso, desprovisto de todo su aparato argumentativo, la confianza originaria en la convergencia de todas las perspectivas en un horizonte universal último, que se acerca notoriamente al postulado weltiano de sentido, puede ser leído dentro de este esquema. Obviamente no podemos aquí desarrollar estos accesos fenomenológicos al fenómeno religioso, pero sí destacar que su estructura común: el hallarse la subjetividad concernida originariamente por la donación de un pathos a partir del cual ella existe a modo de respuesta. De esta manera ya no es la subjetividad un impedimento de la revelación, sino el medio a través de la cual ella acaece. En consecuencia la fenomenología, que describe los modos de esta donación desde la cual la subjetividad es posible y que, por medio de una hermenéutica de la facticidad, los explicita como afecciones o pathos originarios que testimonian la ligazón del sujeto con lo Absoluto, queda legitimada ante la religión en su posibilidad de acceder a la revelación sin desvirtuarla.

Sin embargo, para que esta legimitación sea completa es necesario todavía poner en cuestión el privilegio de la noción de horizonte. La idea de horizonte sigue siendo propia a cada uno de los accesos abiertos por la fenomenología, en cuanto los distintos pathos a través de los cuales lo Absoluto se anuncia siguen presos de un horizonte determinado: el de la vida (Henry), el de la relación ética (Lévinas), el de la existencia como proyección de sentido (Welte), el de la historia (Patocka), etc. ¿Cuál sería, entonces, el verdadero horizonte que podría 
admitir una revelación? O, yendo a la raíz de la cuestión, ¿acepta la revelación un horizonte o excluye por principio todo horizonte en el cual ella pudiera venir a escena? Como advierte Marion (Marion, 2007, 34) este dilema se intensifica si se toma en cuenta que ninguna de las dos hipótesis es en principio aceptable. La revelación, por un lado, no puede ser supeditada a priori a un determinado horizonte sin renunciar a aquella espontaneidad que la define como revelación y verse rebajada a la condición de una manifestación constituida, pues cada horizonte, estableciendo las condiciones de posibilidad de la aparición, posibilita, pero también delimita, lo que en ella puede aparecer y lo que no. Por otro, no es concebible algo que no aparezca en un determinado horizonte. En efecto, «si por principio la revelación excluye todo horizonte, no puede consecuentemente ponerse en escena en ningún lado, para ninguna perspectiva y en ningún fenómeno» (Marion, 2007, 34-35). Ella perdería toda relación a la fenomenalidad y, con ello, a la fenomenología. ¿Cómo habrá de pensarse la relación entre fenomenalidad y horizonte, si ninguno de los dos extremos es admisible? Reinterpretando la solución que el propio Marion da a este dilema, yo diría que el problema sólo acepta ser abordado desde la combinación de la noción de saturación con la de pluralidad de horizontes de revelación y, consecuentemente, de relación religiosa. En efecto, lo revelado puede escapar del dilema en que lo coloca para la fenomenología la noción de horizonte si su revelación satura, esto es, no puede ser contenida por el horizonte en que se da y se abre una y otra vez a nuevos horizontes. El horizonte en el que se experimenta la llamada y, consecuentemente, en el que se inserta la respuesta posibilita que la llamada se anuncie de modo indirecto en el orden de la fenomenalidad, pero no puede agotar la capacidad de apelar y revelarse de lo Divino. La respuesta deja resonar a la llamada, pero no la reproduce ni la acalla. Sus otras resonancias o modulaciones quedan abiertas a ser experimentadas en nuevos horizontes. «La fuerza y la desmesura de aquello que se deja poner en escena sólo puede entrar en los límites del horizonte fenomenológico de un modo tal que lo supera» (Marion, 2007, 35). Esta superación que implica una disolución del horizonte que fuese como marco testimonial es propiamente lo que Marion entiende por saturación. La saturación marca el carácter paradójico de la relación intencional con la revelación. Usualmente la fenomenalidad apunta a una correspondencia plena de intención e intuición: cada mención intencional debe ser plenificada por una intuición. Sin embargo, en la mayoría de los casos y debido a los modos deficientes de donación, la fenomenología debe admitir objetos que no son capaces de plenificar intuitivamente los distintos actos intencionales que apuntan a ellos. Paradójicamente en el caso de 
la saturación lo que se da a intuir supera la intencionalidad que lo intuye y, consecuentemente, el horizonte en el que esa intencionalidad se instala. «Así obliga la revelación a la fenomenología a poner en duda que la verdad se deje reducir a la vivencia de la verdad.» (Marion, 2007, 36). Ahora bien, esta paradoja, por la cual el horizonte, en vez de delimitar a priori lo que en él aparece, se ve saturado por lo que se da a intuir, a mi modo de ver no es estática: no se queda en sí misma ni acaba con su propia formulación, sino sólo adquiere su sentido consumado si tenemos en cuenta aquello a lo que la paradoja remite, a saber, la pluralidad abierta de horizontes en la cual puede acaecer la revelación. En efecto, que la revelación sature el horizonte en el que aparece, que lo supere, que dé a intuir y a significar más de aquello que puede ser captado en ese horizonte implica necesariamente la posibilidad de que la revelación traspase siempre un cierto horizonte hacia nuevos horizontes que tampoco podrán contenerla. Más ello, a su vez, implica una multiplicidad de testimonios de lo infinito y una multiplicidad infinita de vivencia de la relación religiosa, comprendida como experiencia de la revelación. Ninguno de esos horizontes puede, por tanto, en principio ser negado como el «desde donde» de la revelación, pero ninguno tampoco puede pretender contenerla en un todo y excluir a priori otros horizontes. Nadie puede, por ejemplo, negar la Escritura o la Tradición como horizontes de manifestación de lo divino. Pero nadie puede tampoco obligarlo al Espíritu a manifestarse en esos horizontes.

Así, esta idea de saturación y la consecuente multiplicidad de horizontes de revelación juntamente con la admisión del carácter no originario del yo traen una doble consecuencia a la fenomenología. Primero, legitimar su pretensión como fenomenología pático-testimonial de poder acceder al fenómeno religioso sin desvirtuar la revelación que lo testimonia. Segundo, ofrecer un criterio la pluralidad de los horizontes — sobre la base del cual no sólo las distintas religiones positivas pueden entrar en un diálogo no condicionado por «pretensiones exclusivas de verdad», sino desde el cual se vuelven complementarios en lugar de contradictorios los distintos accesos a la relación religiosa abiertos por la propia fenomenología contemporánea.

\section{Conclusiones}

El tercer paradigma de aplicación de la fenomenología a la filosofía de la religión permite no resolver - en el sentido de encontrar una nueva y distinta fun- 
damentación racional unívoca de la comprensión de Dios o una nueva expresión de la esencia común a todas las religiones positivas- pero sí disolver estos problemas de fundamentación y universalidad. Disolver significa aquí poner de manifiesto que tales problemas deben ser reformulados. En efecto, a la luz de este tercer paradigma — que pone en el origen de la religión la relación con una revelación en el sentido amplio de sentirse afectado absolutamente por un pathos que precede la intencionalidad del sujeto y excede todo horizonte - el planteamiento de la cuestión de la universalidad y la fundamentación en los dos primeros no sólo es irresoluble, sino también impertinente. Dicho de modo positivo: es posible acceder a una nueva forma de fundamentación comprendida no como prueba única sino como «legitimación», y a una nueva forma de universalidad comprendida no como esencia única sino como «accesibilidad».

Comencemos por la cuestión de la fundamentación. La fenomenología pático-testimonial no puede, por sí misma, demostrar ni por una deducción lógica o trascendental ni por una constatación empírica que cada una de las afecciones que ella describe tiene su origen efectivamente en lo divino y prueban irrefutablemente la existencia de Dios. Menos aún puede afirmar que de su descripción de estas afecciones sería posible extraer una determinación de cómo hay que comprender unívocamente a Dios, lo cual, por otra parte, sería contradictorio con el carácter de fenómeno saturado de la revelación. La fenomenología pático-testimonial, si quiere tener legitimidad metodológica, debe mantener sus descripciones de estas «afecciones absolutas» en el plano de la vivencia y afirmarlas sólo como tales, sin referirse a la existencia real o no real de su presunto origen. Pero la fenomenología testimonial requiere ser completada por una hermenéutica de la facticidad. Esta «hermenéutica de la facticidad», en el sentido heideggeriano del término, es precisamente quien explicita las distintas afecciones o pathos absolutos que las diferentes corrientes fenomenológicas han descripto como testimonios de la revelación de un fenómeno que se anuncia perforando todo horizonte y constituyendo el origen último de la subjetividad, en cuanto la existencia misma acaece en sus múltiples modos como una respuesta a esa afección absoluta. Dicha hermenéutica de la facticidad no es traída a colación de manera arbitraria por la fenomenología pático-testimonial, sino que es exigida por los fenómenos mismos a los que ella se re-fiere, pues tales fenómenos, por su propio modo de darse y desde sí mismos, solicitan ser explicitados, no sólo para adquirir sentido desde el punto de vista teórico, sino para poder ser asumidos y respondidos. En efecto, la existencia en tanto respuesta a esta afección absolu- 
ta implica haber asumido la interpelación, y ello, a su vez, requiere haberla comprendido de algún modo, haberla explicitado como algo. Sin embargo con esta hermenéutica de la facticidad concurren otras explicitaciones posibles de carácter psicológico, sociológico, científico, etc. Ello pone de manifiesto que la fenomenología pático-testimonial en alianza con una hermenéutica de la facticidad no puede fundamentar en el sentido fuerte de demostrar con evidencias directas la revelación de lo divino. Por otra parte una tal demostración supeditaría lo divino a la razón del sujeto que lo demuestra y, con ello, lo degradaría en su propia divinidad. El límite al que accede la fenomenología testimonial es el de legitimar racionalmente la plausibilidad de la religión o, mejor dicho, de las religiones. Dicho de manera negativa muestra que la religiosidad fundada en la revelación de lo divino que trasciende los poderes del sujeto no es fetichismo encubierto u oscurantismo, sino que es solicitada o requerida desde los fenómenos mismos. Ahora bien, el hombre puede tomar o no en sus manos ese requerimiento, en los múltiples modos en que él acontezca, mientras que no podría decirle «no» ni establecer una relación libre con un factum que tenga fuerza probatoria. Si así fuese la fe no sería confianza, sino certeza; carecería de mérito alguno y el objeto de la fe no sería propiamente una cuestión espiritual, sino intelectual, como lo es toda objetividad cierta en la que las intenciones recubren las intuiciones. De allí también que toda fundamentación determinativa sea para la hermenéutica de la facticidad metodológicamente inaceptable. Ella se limita nada más, pero tampoco nada menos, que a ser un «pensar dejante» (lassendes Denken) que concede — no obliga - legítimamente una ocasión para pensar la relación religiosa como surgida del acaecer de los fenómenos mismos y su dinámica. Como acaecimiento de la relación entre una interpelación y una respuesta la relación religiosa no puede fundamentarse a priori, sino que debe ser vivenciada en su concreta temporalización. Abrir las puertas a la legitimidad de esta vivencia es el modo concreto en que la fenomenología «funda», en el sentido de que «legitima», la posibilidad de la revelación y la religión. Ir más allá de esas puertas y querer demostrar la verdad objetiva de la revelación (que justamente no es un objeto, sino el origen de la subjetividad del sujeto) o de una cierta religión trae de nuevo a primer plano la sospecha de que detrás de la fenomenología de la religión se esconde una filosofía religiosa.

A esta nueva concepción de la idea de «fundamentación» le corresponde una nueva idea de universalidad. La universalidad de la religión no se encontraría en ninguna esencia abstracta, construida comparativamente, y que representaría el 
núcleo racional verdadero por el cual habría de medirse toda religión. Antes bien ella radica en el hecho de que cada uno de los testimonios de lo divino o de la apelación reveladora de Dios está abierto a todo hombre en tanto tal, independientemente de su confesión religiosa y del horizonte concreto desde el cual reciba la apelación. La universalidad de la revelación y, consecuentemente, de la religión como relación con la revelación radica en el carácter universal de la afección (en sus múltiples modos de acaecer) a través de lo cual lo Divino se testimonia. Y esa universalidad de la afección ancla, a su vez, en el hecho de que ella se dirige al hombre en tanto tal, a su condición de sujeto, y, por tanto, a todo hombre, pues todo hombre ya siempre se halla afectado por una interpelación absoluta ${ }^{10}$. Ciertamente él se cerrará o no ante ella, asumirá de un modo u otro esa afección y la respuesta que surja de esa asunción se integrará o no en el horizonte de una religión particular. De allí que se disuelva la necesidad de encontrar una esencia común a todas las religiones, en la medida en que se coloca la universalidad de

${ }^{10}$ La multiplicidad de relaciones religiosas y el hecho de que ninguna de ellas agote la interpelación infinitamente excedente de lo divino no excluye el preguntar crítico por las formas decadentes de religiosidad orientadas hacia la idolatría y caracterizadas por contradecir, por su modo mismo de efectuarse en el mundo, las características formales de la interpelación. El núcleo de esta contradicción radica en pretender poder dar cuenta de un único cómo de la revelación y, consecuentemente, subordinarla a lo que arriba hemos llamado, siguiendo a Welte, una cierta esfera de mediación, es decir, a un conjunto de ritos, normas, dogmas, cultos, etc. a través de los cuales el acontecimiento religioso existencial se in-stituye en el mundo público como una realidad objetiva. En otras palabras, una religión se vuelve dogmática cuando pretende detener el carácter vivo, aconteciente y pluri-horizontal de la revelación y someterlo a una representación mediadora y objetiva de lo divino que responde a la comprensión o intereses de un determinado individuo o colectivo social. La forma degradada por excelencia de la religión, el fundamentalismo, se degrada no por afirmar que Dios se revela al fundamentalista del signo que fuese de éste o aquel otro modo, sino por afirmar que sólo se le puede revelar así al hombre, desconociendo que la revelación, por su carácter de acontecimiento aconteciente no puede determinarse por anticipado y que la condición humana no es agotada por ninguna de sus concreciones culturales. Por ello mismo una hermenéutica fenomenológica de la relación religiosa debe poder incluir una patología de lo religioso y encontrar criterios que permitan deslindar la genuina relación religiosa de sus formas degradadas. Ésta es, sin embargo, una tarea que excede este trabajo. Empero al lector interesado puedo remitirlo a otro trabajo mío en el que enfoco el tema de modo central: «La vía del sentido y el sentido de la vía. El acceso a la experiencia religiosa y las formas degradadas de la religión en el pensamiento de Bernhard Welte», en: Stromata 1/2, Nro. 67 (2011), pp. 61-87. Además Bernhard Casper en su excelente libro Das Ereignis des Betens. Grundlinien einer Hermeneutik des religiösen Geschehens, Freiburg/ München, Alber, 1998, pp. 137-152 ha intentado trabajar de manera orientativa los criterios paradigmáticos para deslindar las formas genuinas de las no genuinas de relación religiosa.

ÉNDOXA: Series Filosóficas, n. ${ }^{\circ}$ 29, 2011, pp. 249-282. UNED, Madrid 
la religión ya no en sus manifestaciones positivas, sino en aquello que las hace posibles: la revelación de lo absoluto que, de infinitos e inagotables modos, se dirige a todo hombre no en tanto adscrito a tal o cual fe, sino por su propia condición de sujeto.

Una concepción de la fenomenología de la religión que reinterprete en los términos que aquí se lo ha hecho las ideas de fundamentación y universalidad puede, por cierto, no contentar las aspiraciones de verdad absoluta que han sido propias de las distintas religiones positivas y sus dogmas a lo largo de la historia, pero acepta sus propios límites y, aceptándolos, no sólo disuelve los problemas de los paradigmas anteriores, sino que, a la par, nos deja pensar por qué el espíritu en verdad «sopla de donde quiere».

\section{Referencias bibliográficas}

Casper, B. (2004). «Möglichkeiten, Grenzen und Chancen einer Philosophie der Religión— heute», en: Enders M. y Zaborowski H. (eds.). Phänomenologie der religión. Zugänge und Grundfragen, Freiburg/München: Alber, pp. 11-26.

Courtine, J-F. (1992). «Phénoménologie et herméneutique de la religion», en: Chrétien, J-L; Henry, M. ; Ricoeur, P. y Marion, J-L. Phénoménologie et Théologie, París: Criterion, pp. 7-14.

GreisCH, J. (2004). «Die hermeneutische Wende der Religionsphilosophie», en: Enders M. y Zaborowski H. (eds.). Phänomenologie der religión. Zugänge und Grundfragen, Freiburg/München: Alber, pp. 101-121.

Heidegger, M. (1957). «Die onto-theo-logische Verfassung der Metaphysik», en: Heidegger M. Identität und Differenz, Pfullingen: Neske, pp. 31-67.

- (1977). Gesamtausgabe, Band 2: Sein und Zeit, Frankfurt a. M.: V. Klostermann.

- (1995). Gesamtausgabe, Band 63: Ontologie (Hermeneutik der Faktizität), Frankfurt a. M.: V. Kostermann.

HeLd, K. (2009). «Phänomenologische Begründung eines nachmetaphysischen Gottesverständnisses», en: Söding, T. / Held, K. (eds). Phänomenologie und Theologie, Freiburg/Basel/Wien: Herder, pp. 9-27.

Henry, M. (1992).»Parole et religión: la Parole de Dieu», en: Chrétien, J-L; Henry, M. ; Ricoeur, P. y Marion, J-L. Phénoménologie et Théologie, París: Criterion, pp. 129-160. 
Hussert, E. (1950). Gesammelte Werke-Husserliana, Vol III/1: Ideen zu einer reinen Phänomenologie und phänomenologischen Philosohie. Erstes Buch, Den Haag: Martinus Nijhoff.

Marion, J-L. (2007). «Aspekte der Religionsphänomenologie: Grund, Horizont und Offenbarung», en: Gabel M. y Joas H. (eds.). Von der Ursprünglichkeit der Gabe, Freiburg/München: Karl Alber, pp. 15-36.

Ricoeur, P. (1992). «Expériencie et langage dans le discours religieux», en: Chrétien, JL; Henry, M. ; Ricoeur, P. y Marion, J-L. Phénoménologie et Théologie, París: Criterion, pp. 15-39.

SCHAEFFLER, R. (2002). Religionsphilosophie, Freiburg/München: Karl Alber.

Scheler, M. (1965). Gesammelte Werke, Band 5 : Vom ewigen im Menschen, Bern: Francke Verlag.

Trawny, P. (2009). «Wie Gott vertrauen? Bemerkungen zu Klaus Held 'phänomenologischer Begründung eines nachmetaphysischen Gottesverständnisses im Rückgang auf Heideggers Paulus-Interpretation», en: Söding, T. / Held, K. (eds.). Phänomenologie und Theologie, Freiburg/Basel/Wien: Herder, pp. 121-132.

Welte, B. (2008). «Vom Wesen und Unwesen der Religion», en: Welte, B. Gesammelte Schriften, Vol III/2: Kleinere Schriften zur Philosophie der Religion, Freiburg: Herder, pp. 40-58.

Recibido: 8 /06/2011

Aceptado: 29/03/2012 